\title{
Chile ratifica la Convención Interamericana contra el Terrorismo
}

José Zalaquett*

\section{Introducción}

La Convención Interamericana contra el Terrorismo (en adelante, Convención Interamericana o CICT) se adoptó en Bridgetown, Barbados, el 3 de junio de $2002^{1}$. La ratificación de esta convención por parte de Chile se promulgó por el Decreto Supremo 263, de 25 de noviembre de 2004, el cual fue publicado en el Diario Oficial el 10 de febrero de 2005.

Con este acto, Chile incorporó a su derecho interno un nuevo tratado internacional contra el terrorismo, el cual se suma a una larga lista de instrumentos internacionales sobre esta materia previamente ratificados por el país, tanto multilaterales (de Naciones Unidas como de la Organización de Estados Americanos) como bilaterales. De hecho, todos los instrumentos a que hace referencia el artículo 2 de la Convención Interamericana (ocho convenios y dos protocolos acordados entre 1970 y 1999) habían sido ya ratificados por Chile con anterioridad ${ }^{2}$.

En este comentario se examina sucintamente lo siguiente: (i) el significado de la Convención Interamericana dentro de la evolución de la normativa internacional contra el terrorismo; (ii) la cuestión de la definición o conceptualización del terrorismo y cómo esta se aborda en la Convención Interamericana; (iii) las obligaciones que impone esta convención al Estado de Chile, tomando en consideración la legislación chilena contra el terrorismo.

\section{Evolución de la normativa internacional contra el terrorismo}

Tal como ha destacado la Comisión Interamericana de Derechos Humanos $(\mathrm{CIDH})$, el terrorismo (o la comisión del tipo de actos que son en la actualidad generalmente considerados como ataques terroristas) dista de ser un fenómeno nuevo; en efecto, "podría incluso decirse que es anterior a la historia registrada"3. En cambio, los términos "terrorismo" y "terrorista" son de uso más reciente, habiéndose asentado algunas de las principales connotaciones que hoy se asignan a estas expresiones, a partir de la segunda mitad del siglo XIX ${ }^{4}$. Por su parte, el comienzo del tratamiento más o menos sistemático del terrorismo, como materia de derecho internacional, se remonta a $1970^{5}$. El más reciente listado actualizado de Naciones Unidas sobre convenciones y protocolos multilaterales contra el terrorismo incluye trece instrumentos internacionales y siete de carácter regional ${ }^{6}$.
* Codirector del Centro de Derechos Humanos de la Facultad de Derecho de la Universidad de Chile.

1 Conforme a lo dispuesto en su artículo 22, la Convención Interamericana entró en vigor con fecha 10 de junio de 2003, fecha en que fue depositado el sexto instrumento de ratificación.

2 Con respecto a la obligación que establece el artículo 6 de la CICT, sobre tipificación del delito de lavado de dinero, se puede considerar que con la Ley №19.913 de Chile, de 18 de diciembre de 2003 (que complementa la anterior ley sobre esta materia, №19.366, de enero de 1995), se ha terminado por satisfacer razonablemente esta exigencia.

3 Ver $\mathrm{CIDH}$, Informe Sobre Terrorismo y Derechos Humanos, Secretaría General de la Organización de Estados Americanos, Washington, D.C., 2002, p. 17.

Este comentario, junto con el documento principal a que se refiere, están disponibles en www.anuariocdh.uchile.cl 
4 Ver Laquear, Walter, Terrorism, Little, Brown, and Company, Boston-Toronto, 1977, Capítulo 1: "The Origins".

5 En rigor, el primer instrumento de este tipo de la posguerra fue el Convenio sobre las Infracciones y Ciertos Otros Actos Cometidos a Bordo de las Aeronaves, firmado en Tokio, el 14 de septiembre de 1963, pero sus disposiciones fueron superadas por sucesivas convenciones sobre ese tema (ver nota número 6) y es a partir de comienzos de los años 70 que el desarrollo normativo sobre esta materia avanza de modo sostenido.

6 Ver http:// untreaty.un.org/ English/Terrorism.asp, sitio consultado el 8 de mayo de 2005.

7 Ver, por ejemplo, Laqueur, op. cit.; Conor Gearty, Terror, Faber and Faber Limited, Londres, 1991; Lambert, Joseph J., Terrorism and Hostages in International Law, Grotius Publications Limited, Cambridge, Reino Unido, 1990.
Esta evolución se explica por una mayor frecuencia de actos terroristas de carácter internacional o perpetrados en países de alta visibilidad mundial, a partir de la década de los años sesenta, por la más amplia difusión de estos hechos y, principalmente, por las preocupaciones que su proliferación han generado en las autoridades políticas y en la opinión pública de distintas naciones, respecto del riesgo que entrañan para la protección de las personas, la seguridad y el orden público dentro de los Estados y la paz internacional.

La literatura sobre el desarrollo del terrorismo, que se ha producido a partir de la década de los años setenta, coincide en resaltar los distintos factores que contribuyen a explicar la mayor incidencia e impacto de las formas de terrorismo de las últimas décadas: ciertas posiciones ideológicas que justifican este tipo de actos como estrategia de lucha política; la mayor disponibilidad y menor costo de explosivos y otros elementos de ataque indiscriminado; la creciente facilidad del transporte internacional; la vulnerabilidad de los espacios públicos de las grandes ciudades, así como la posibilidad de ocultamiento que estas ofrecen, y los medios masivos y globales de comunicación que permiten que la publicidad del acto terrorista sea de alcance mundial e instantáneo ${ }^{7}$.

Frente a todo lo anterior, el ataque terrorista perpetrado en Estados Unidos en contra de las Torres Gemelas de Nueva York y del edificio del Pentágono, el 11 de septiembre de 2001, así como los diversos atentados terroristas que pueden ser atribuidos a Al Qaeda o a grupos afines, que se sucedieron posteriormente, en contra de blancos en ciudades y establecimientos de Europa, Norte de África y el Lejano Oriente, son percibidos generalmente como un fenómeno cualitativamente más grave y amenazante. Muchas de las políticas adoptadas por el Gobierno de Estados Unidos para enfrentar esta amenaza han sido objeto de intensa controversia, en ese mismo país y en el plano internacional. Sin embargo, cualquiera que sea la explicación que se dé sobre las causas de fondo de la emergencia de organizaciones, redes y células descentralizadas, de inspiración fundamentalista, y de su determinación y voluntad de autoinmolación, permanece el hecho de la capacidad de estas de actuar internacionalmente de modo invisible y ubicuo, así como su habilidad para llevar a cabo ataques terroristas con un poder inédito de destrucción, contra blancos o en sitios de gran relevancia y simbolismo para los países que ellos consideran enemigos.

Estos desarrollos constituyen el antecedente inmediato detrás del impulso para la elaboración de la Convención Interamericana y otros recientes instrumentos internacionales.

\section{Definición o conceptualización del terrorismo}

Bien señala la CIDH lo siguiente:

"Con el objeto de encuadrar el concepto de terrorismo dentro del marco del derecho internacional, debe reconocerse en primer lugar que el lenguaje del terrorismo se utiliza en una variedad de contextos y con distintos grados de formalidad, para caracterizar: 
- acciones, que incluyen formas de violencia como los secuestros.

- actores, incluidas personas u organizaciones.

- causas o luchas, en que la causa o lucha puede estar tan marcada por la violencia terrorista que la hacen indistinguible de esta, o en que un movimiento puede cometer actos aislados de terrorismo o emprender estrategias terroristas. Es particularmente en este sentido que se ha planteado la falta de acuerdo en torno a una definición integral del terrorismo, debido a que ciertos Estados han considerado que lo que con frecuencia se denominan "movimientos de liberación nacional" y sus metodologías deben ser excluidos de toda definición de terrorismo en razón de su asociación con el principio de libre determinación de los pueblos.

- situaciones en que la violencia terrorista es un problema particularmente grave o difundido en una región, Estado u otra zona.

- conflictos armados en el sentido, por ejemplo, de la denominada "guerra contra el terrorismo" posterior al 11 de septiembre de $2001^{\prime \prime}$.

Frente a estas distintas posibilidades, la normativa internacional se ha inclinado principalmente por caracterizar o tipificar acciones terroristas.

A este respecto, la doctrina acepta que no hay uniformidad de criterios para definir una acción terrorista. Sin embargo, pocos dudarían de aplicar tal caracterización a un acto que reuniera los siguientes rasgos: (i) que se use o amenace usar la fuerza contra civiles o de de modo indiscriminado; (ii) que tal uso o amenaza sea un medio de combate o elemento de una estrategia para lograr ciertos objetivos ideológicos o políticos (incluidos los de inspiración religiosa y también los objetivos buscados por el crimen organizado para conseguir la impunidad u otras concesiones por parte del poder político); (iii) que se procure conseguir dichos fines induciendo un estado de miedo en la población o en sectores de ella y/o procurando una respuesta de las autoridades -sea una reacción débil o excesivaque se estima favorecerá tales objetivos; (iv) que se busque la más amplia publicidad posible de los actos.

En los distintos instrumentos internacionales sobre la materia se han seguido los siguientes caminos, en lo que toca a la caracterización de actos terroristas:

(a) En cada una de las convenciones en contra de actos específicos, se establecen definiciones y se describen conductas relacionadas con dichos actos, tales como el secuestro de aeronaves, los ataques contra personas internacionalmente protegidas, la toma de rehenes, el atentado con bombas u otros artefactos mortíferos, y el terrorismo nuclear.

(b) En el Convenio Internacional para la Represión de la Financiación del Terrorismo, un instrumento de carácter más general, se hace aplicable su contenido a todos los actos descritos en las convenciones internacionales que menciona. A ello se agrega una descripción más general del siguiente tenor: 
9 Op. cit. nota 4.

${ }^{10}$ Ejemplos claros (aunque no los únicos) de tales normas en la Convención Americana sobre Derechos Humanos son las prohibiciones categóricas, como la que contienen las normas que proscriben la tortura y los tratos o castigos crueles, inhumanos o degradantes (artículo 5), la censura previa de toda forma de expresión (salvo la calificación de espectáculos públicos para la protección de la infancia y la adolescencia) (artículo 13) o la prohibición de la prisión por deudas (artículo 7).
"Artículo 2.1.b:

Cualquier otro acto destinado a causar la muerte o lesiones corporales graves a un civil o a cualquier otra persona que no participe directamente en las hostilidades en una situación de conflicto armado, cuando el propósito de dicho acto, por su naturaleza o contexto, sea intimidar a una población u obligar a un gobierno o a una organización internacional a realizar un acto o a abstenerse de hacerlo".

(c) La Convención Interamericana que comentamos opta por señalar, en su artículo 2.1, que para los propósitos de dicha Convención se entienden por "delito" aquellos establecidos en los diez instrumentos internacionales que detalla a continuación. Dado que entre ellos se encuentra el Convenio Internacional para la Represión del Financiamiento del Terrorismo, debe concluirse que también se incluye la descripción más general contenida en el artículo 2.1.b. de esta, recién transcrito.

Con la salvedad antedicha, puede afirmarse, entonces, que la CICT no representa un cambio de la tendencia de la normativa internacional a eludir una definición o conceptualización del terrorismo, prefiriendo una enumeración de conductas que se considera tienen tal carácter. Es acertado lo dicho en el Informe de la Comisión Interamericana de Derechos Humanos, en el sentido de que, aparte de las dificultades de orden teórico que implica tal conceptualización, una definición más integral es resistida por diversos Estados que temen que por esa vía se estigmatice a determinados movimientos o causas políticas ${ }^{9}$.

\section{Obligaciones que impone la CICT al Estado de Chile}

La gran mayoría de las disposiciones de los instrumentos internacionales contra el terrorismo no contienen normas Ilamadas "self executing", o autoaplicables, esto es, aquellas que pueden aplicarse directamente en el ámbito de las jurisdicciones nacionales por el solo hecho de haberse incorporado el respectivo tratado o convención al derecho interno, sin mediar acto legislativo o medidas de carácter administrativo ${ }^{10}$.

En cambio, dichos instrumentos establecen, sobre todo, obligaciones de carácter programático, o bien, que requieren de medidas especiales, sean legislativas o administrativas, por parte del Estado y, por tanto, suponen un determinado proceso que involucra tiempo, recursos y la participación, a veces, de más de un poder del Estado. Algunas de estas obligaciones pueden ser caracterizadas como de medio o comportamiento. Otras son obligaciones de resultado, pero de cumplimiento progresivo, entendiéndose que es deber de los Estados adoptar diligentemente las medidas necesarias para alcanzar el resultado esperado como, por ejemplo, tipificar determinadas conductas como delitos en su legislación interna.

Tres normas de la CICT, sin embargo, tienen un claro carácter autoaplicable: las cláusulas de no discriminación (artículo 14), la de derechos humanos (artículo 15) y la llamada cláusula de 
"despolitización", la cual, para los propósito de extradición o asistencia jurídica mutua, determina que ninguno de los delitos establecidos en los instrumentos internacionales que enumera el artículo 2, se considerará como delito político o delito conexo con un delito político o un delito inspirado por motivos políticos (artículo 11). Esta última cláusula tiene por objeto impedir que se denieguen la extradición o la asistencia jurídica por la sola razón de estimarse que hay un elemento político presente en el delito en cuestión.

En cuanto a la obligación de los Estados Parte de esforzarse por ser parte de los diez instrumentos internacionales enumerados en el artículo 2 de la CICT (artículo 3), Chile, como queda dicho, ya los ha ratificado todos.

Con respecto a la adecuación del derecho interno chileno al derecho internacional, mediante la tipificación como delitos de las conductas descritas en los distintos instrumentos internacionales contra el terrorismo de que Chile es parte, es preciso remitirse al texto actualizado de la Ley № 18.314, de 17 de mayo de 1984, que Determina Conductas Terroristas y Fija su Penalidad, cuya última modificación fue introducida el 11 de noviembre de 2005, mediante la Ley № 20.074 ${ }^{11}$. Los artículos 1 y 2 de esta ley tipifican delitos terroristas en términos que se puede estimar que incluyen las descripciones de conductas ilícitas contenidas en los instrumentos internacionales contra el terrorismo, e incluso van, en ciertos puntos, más allá de tales descripciones, aspecto sobre el cual el derecho internacional no se pronuncia (sin perjuicio de que otros Estados puedan sentirse obligados a la asistencia jurídica mutua con Chile o a respetar las normas sobre extradición en sus relaciones con el Estado chileno sólo respecto de aquellas conductas tipificadas como terroristas en la legislación de este que calcen con las descripciones establecidas en los instrumentos internacionales).

La Convención Interamericana, a diferencia de diversos otros instrumentos internacionales contra el terrorismo, no contiene una cláusula que permita a los Estados establecer su jurisdicción extraterritorial para juzgar actos terroristas cometidos por sus ciudadanos (principio de personalidad activa) o en contra de ellos (principio de personalidad pasiva), ni tampoco el principio de aut dedere aut judicare, esto es, la obligación del Estado en cuya jurisdicción se encuentre una persona de quien se presume ha sido partícipe de un acto terrorista, de extraditarla a un Estado que pueda tener jurisdicción para juzgarlo (sobre la base de los principios de territorialidad, personalidad activa o personalidad pasiva), o bien, de juzgarlo en su propio territorio.

Por el contrario, el artículo 19 de dicho instrumento establece que:

"Nada de lo dispuesto en la presente Convención facultará a un Estado Parte para ejercer su jurisdicción en el territorio de otro Estado Parte ni para realizar en él funciones que estén exclusivamente reservadas a las autoridades de ese otro Estado Parte por su derecho interno".

Tanto la ausencia de una cláusula de jurisdicción extraterritorial como esta norma del artículo 19 se explican por el temor de muchos Estados
11 El texto actualizado de la Ley № 18.314 puede consultarse en www.anuariocdh.uchile.cl 
americanos de que Estados Unidos pudiera sentirse autorizado por esta Convención para detener personas o desarrollar actividades de inteligencia dentro de sus respectivas jurisdicciones.

La Convención Interamericana sí contiene otras cláusulas que se encuentran frecuentemente en instrumentos de este tipo: la de denegación de la condición de refugiado (artículo 12) y del otorgamiento de asilo (artículo 13) para las personas respecto de las cuales haya motivos fundados para considerar que han cometido un delito establecido en los instrumentos internacionales mencionados en el artículo 2 de la convención. En ambos casos, la obligación que se establece es de resultado, pero de cumplimiento progresivo, estableciéndose la obligación de los Estados Partes de adoptar las medidas que corresponda, de conformidad con las disposiciones pertinentes de derecho interno e internacional, para alcanzar dichos propósitos.

Las normas propiamente distintivas de la Convención Interamericana se encuentran en los artículos 4, 5, 6, 7, 8 y 10, sobre prevención, combate y erradicación de la financiación del terrorismo y sobre diversas formas de cooperación entre los Estados para aplicar la ley, controlar la circulación internacional de terroristas y brindarse asistencia jurídica mutua para la prevención, investigación y proceso de estos delitos. El artículo 10 es especialmente novedoso al contemplar (aunque con numerosas condiciones y salvaguardas) la posibilidad de traslado de una persona que se encuentre detenida o cumpliendo una condena en el territorio de un Estado Parte, cuya presencia se solicite en otro Estado Parte para fines de prestar testimonio o de identificación o para que ayude a obtener pruebas necesarias para la investigación o el enjuiciamiento de delitos terroristas.

El cumplimiento de las distintas obligaciones que asumen los Estados Partes de la CICT no está entregado a ningún órgano jurisdiccional de carácter regional. Queda confiado, fundamentalmente, al honor de los Estados. Sin perjuicio de ello, una disputa entre Estados a propósito de la aplicación de la Convención Interamericana podría llegar a ser conocida por la Corte Internacional de Justicia, si las partes han aceptado su jurisdicción, con alcance general o especial. En la esfera política, los Estados Partes de la Convención Interamericana se comprometen a propiciar la más amplia cooperación en "el ámbito de los órganos pertinentes de la organización de Estados Americanos, incluido el Comité Interamericana contre el Terrorismo (CICTE)" (artículo 19).

La determinación de en qué medida Chile ha cumplido con las obligaciones que ha asumido en virtud de las normas antedichas, en especial, los artículos 4 y 8, escapa a los límites de este comentario. Cabe señalar en este punto que una tarea pendiente para las autoridades estatales y el mundo académico chileno es realizar un estudio del grado de cumplimiento de las obligaciones que le imponen a Chile los tratados multilaterales de que es parte, sobre derechos humanos, derecho internacional humanitario, derecho de los refugiados y normativa internacional antiterrorista. 